\title{
Motivações, Desafios e Dificuldades Vivenciados por Psicólogos Empreendedores: Estudo Qualitativo
}

\author{
Dhayanne de Sousa Silva ${ }^{1}$ \\ ${ }^{1}$ Universidade Federal de Uberlândia, MG, Brasil. \\ Heila Magali da Silva Veiga ${ }^{1}$ \\ ${ }^{1}$ Universidade Federal de Uberlândia, MG, Brasil. \\ Pedro Afonso Cortez \\ ${ }^{2}$ Universidade Metodista de São Paulo, SP, Brasil.
}

\begin{abstract}
Resumo:O empreendedorismo se apresenta como uma forma de inserção profissional em contextos de precarização das relações de trabalho e emprego. No entanto são escassas as produções sobre o tema, o que torna emergente produzir compreensões sobre empreendedorismo entre psicólogos. Neste estudo, objetivou-se identificar motivações, desafios e dificuldades relatados por psicólogos empreendedores. A pesquisa foi qualitativa com aplicação de entrevista semiestruturada em seis psicólogos empreendedores do estado de Minas Gerais. Os relatos foram categorizados por meio de análise de conteúdo, permitindo identificar motivações, desafios e dificuldades enfrentados por psicólogos no processo empreendedor. Essas evidências contribuem com um mapeamento inicial sobre empreendedorismo entre psicólogos, demandando que estudos futuros verifiquem a saturação teórica e validade empírica dos resultados em outros contextos e amostra. A principal contribuição da investigação se refere à abdução de que os conteúdos e práticas relativos ao empreendedorismo e gestão de negócios são importantes na graduação em Psicologia para potencializar o processo empreendedor entre psicólogos. Para tanto, demanda-se que profissionais, pesquisadores e entidades incluam o empreendedorismo entre os tópicos a serem desenvolvidos pela categoria em favor de uma psicologia que preserve a pluralidade da prática profissional.
\end{abstract}

Palavras-chave: Psicólogos, Empreendedores, Profissões, Educação Empreendedora, Formação Profissional.

\section{Motivations, Challenges and Difficulties Experienced by Entrepreneurial Psychologists: Qualitative Study}

\begin{abstract}
Entrepreneurship maximizes professional opportunities in precarious job and labor contexts. However, productions on the theme are scarce, which makes important producing about entrepreneurship practices in Psychology. this paper aimed to identify motivations, challenges and difficulties reported by entrepreneurial psychologists. We used the qualitative method with semi structured interview in six Brazilian entrepreneurial psychologists. Interview reports were analyzed through content analysis to identify motivations, challenges and difficulties faced by psychologists in the entrepreneurial process. This study shows an initial mapping of entrepreneurship among psychologists, requiring that future studies verify the theoretical saturation and empirical validity of results in other contexts and samples. The main contribution is the centrality of entrepreneurship and management content in psychology graduation to improve the entrepreneurial process among psychologists. For such purpose, professionals, researchers and entities must include the entrepreneurship as one topic developed by Brazilian psychologists that preserves the plurality of professional practice.
\end{abstract}

Keywords: Psychologists, Entrepreneurs, Occupations, Entrepreneurial Education, Professional Education. 


\title{
Motivación, Desafíos y Dificultades Vividas por Psicólogos Emprendedores: Estudio Cualitativo
}

\begin{abstract}
Resumen: El emprendimiento es una de las formas de inserción profesional en contextos de precarización de las relaciones de trabajo y empleo. Sin embargo, son escasas las producciones científicas sobre el tema, lo que hace emergente producir investigaciones sobre el emprendimiento entre psicólogos. En el presente estudio, se objetivó identificar motivaciones, desafíos y dificultades relatadas por psicólogos emprendedores. La investigación fue cualitativa con aplicación de entrevista semiestructurada a seis psicólogos emprendedores del estado de Minas Gerais (Brasil). Los relatos fueron categorizados por medio de análisis de contenido, permitiendo identificar motivaciones, desafíos y dificultades enfrentadas por psicólogos en el proceso emprendedor. Esta evidencia contribuye con un mapeo inicial sobre emprendimiento entre psicólogos, y estudios futuros pueden verificar la saturación teórica y validez empírica de los resultados en otros contextos y muestras. La principal contribución de la investigación se refiere a la abducción de que los contenidos y prácticas relativas al emprendimiento y gestión de negocios son importantes en la graduación en Psicología para potenciar el proceso emprendedor entre psicólogos. Para ello, se requiere que profesionales, investigadores y entidades incluyan el emprendimiento entre los temas que desarrollar en favor de una psicología que preserve la pluralidad de la práctica profesional.
\end{abstract}

Palabras clave: Psicólogos, Emprendedores, Profesiones, Educación Emprendedora, Formación Profesional.

\section{Introdução}

O desemprego apresentou uma tendência crescente nos últimos anos. No ano de 2017, o número de desempregados no país foi recorde e ultrapassou a marca de 13 milhões de trabalhadores (Instituto Brasileiro de Geografia e Estatística, 2017), índice esse que permaneceu elevado nos anos seguintes, sendo de 12,4 milhões de trabalhadores desempregados no primeiro trimestre de 2019 (Instituto Brasileiro de Geografia e Estatística, 2019). Nesse cenário, um desafio com o qual se deparam os diplomados com habilitação superior é conseguir inserção no mercado de trabalho. Essa realidade não é diferente para os psicólogos, que também tendem a enfrentar dificuldades em se sustentar exclusivamente com sua prática profissional, principalmente nos primeiros dois anos, como egressos da universidade (Bastos \& Gondim, 2010).

Diante dessa realidade, fomentar o empreendedorismo no ensino superior se constitui como um importante instrumento para inserção profissional dos egressos das universidades, incluindo os alunos diplomados por meio da psicologia. De maneira geral, o empreendedorismo tende a proporcionar desenvolvimento econômico e, consequentemente, impactar na geração de empregos (Liñán, Rodríguez-Cohard, \& RuedaCantuche, 2011; Mars \& Rios-Aguillar, 2010) e maximizar a inserção social (Alvord, Brown, \& Letts, 2004).

Numa produção sobre as alternativas ocupacionais dos psicólogos, notou-se que há ampliação na atuação desse profissional em áreas voltadas às políticas públicas, assistenciais, organizacionais e educacionais. Especialmente na área de políticas públicas, essa inserção tem destacado o compromisso social da profissão (Andrade, Braga, Souza, \& Gomes, 2017; CFP, 2016), sendo o Sistema Único de Assistência Social (Suas) um dos principais campos de emprego para os psicólogos (Conselho Federal de Psicologia \& Centro de Referência Técnica em Psicologia e Políticas Públicas, 2011). Ademais, a Norma Operacional Básica de Recursos Humanos do Suas prevê a presença do psicólogo nas equipes de serviços integrados ao Suas (Brasil, 2006). Ainda assim, a prática clínica continua sendo a que mais atrai os profissionais (Bastos \& Gondim, 2010). Em diferentes contextos de atuação, além do manejo das atividades estritamente atribuíveis aos psicólogos, também são requeridas habilidades de gestão administrativa e empreendedorismo por parte 
do psicólogo para assegurar o funcionamento dos serviços prestados. Assim, pela possibilidade de o empreendedorismo otimizar as condições de atuação da categoria, torna-se fundamental compreendê-lo entre psicólogos (Ribeiro, Fernandes, \& Diniz, 2016).

Considerando-se as produções sobre conhecimentos aplicados à prática profissional do psicólogo, o estudo do empreendedorismo na categoria profissional ainda se mostra lacunar (Andrade, Pissaia, Oliveira, \& Silva, 2016). Embora se identifiquem iniciativas do Conselho Federal de Psicologia de trazer a questão da profissionalização do psicólogo à tona, muitas vezes, a compreensão da atuação por meio de práticas específicas, como é o caso dos psicólogos empreendedores, demandam análise pormenorizada para que sejam compreendidas suas particularidades (Seixas, Coelho-Lima, \& Costa, 2010).

Nesse sentido, investigações qualitativas que busquem dimensionar o fenômeno na realidade vivenciada pela própria categoria podem contribuir no mapeamento conceitual da atuação dos profissionais da área, com o intuito de otimizar a compreensão de práticas empreendedoras entre psicólogos (Cortez \& Veiga, 2018; Lamas, Ambiel, \& Silva, 2014). Neste estudo, o empreendedorismo é compreendido como um processo interativo de geração de negócios, o qual perpassa desde criar a ideia de negócio até a efetivação do projeto na realidade. Esse processo é realizado pelo sujeito empreendedor, que reúne características pessoais e competências para concretizar a proposta de negócio (Hjorth, Holt, \& Steyaert, 2015). Tendo esse mote, o objetivo deste estudo foi identificar motivações, desafios e dificuldades relatados por psicólogos empreendedores ao longo do processo de proposição do próprio negócio relacionado à prestação de serviços psicológicos.

\section{Método}

A presente pesquisa pode ser classificada como qualitativa, uma vez que há interação contínua entre participantes e pesquisador, ou seja, o foco está no processo e, a partir das trocas, as quais são permeadas por questões históricas, econômicas, sociais, políticas e culturais, o pesquisador busca a compreensão da lógica interna do fenômeno (Minayo, 2012).

\section{Participantes}

Para seleção dos participantes do estudo, foram definidos como critérios de inclusão: a) o profissional deveria possuir registro profissional ativo em seu órgão de classe, o que foi comprovado pelo cadastro nacional de psicólogos disponibilizado pelo Conselho Federal de Psicologia em seu sítio eletrônico; b) ser sócio ou proprietário de um empreendimento na área de psicologia; e c) exercer a atividade profissional como psicólogo empreendedor há pelo menos um ano, pois, com esse período de tempo, os profissionais teriam experiência considerável na gestão de seu próprio negócio, podendo responder às perguntas de pesquisa de forma apropriada.

O tamanho amostral foi definido por meio do critério de saturação do conteúdo. Isto é, a inclusão de novos participantes não acrescentaria informações adicionais ao tema mediante aquelas já obtidas, pois o conteúdo relatado apenas repetia informações reunidas em relatos anteriores (Francis et al., 2010). Considerando os critérios estabelecidos, foi selecionada uma amostra de conveniência composta por seis psicólogos empreendedores $(n=6)$ de uma cidade do estado de Minas Gerais. A maior parte da amostra foi feminina $(n=5)$, sendo três empreendedoras na área clínica, duas na área de avaliação psicológica em psicologia do trânsito e um psicólogo dono de consultoria na área de gestão de pessoas. A idade dos participantes variou de 26 a 41 anos e todos eram egressos de graduação em Psicologia de uma instituição pública federal mineira.

\section{Instrumento}

O instrumento para coleta de dados foi um roteiro de entrevista semiestruturada para dirigir a verbalização do participante para temas relativos aos problemas da investigação, a saber, empreendedorismo entre psicólogos (Kallio, Pietilä, Johnson, \& Kangasniemi, 2016). Entre as questões apresentadas no instrumento, foram propostas as seguintes indagações: a) você recebeu algum incentivo ou apoio de alguém para abrir sua própria clínica ou consultoria?; b) o que te motivou a abrir seu consultório/clínica/empresa?; c) você enfrentou dificuldades na proposição e gerenciamento de seu consultório/clínica/empresa? Em relação aos aspectos demográficos, foram registrados: a) área de atuação; b) gênero; c) idade; $\mathrm{e}$ d) tempo de exercício da atividade profissional como psicólogo empreendedor.

\section{Procedimentos}

A investigação foi submetida ao Comité de Ética em Pesquisa com Seres Humanos da Instituição 
Propositora da investigação. A aprovação para execuçãodainvestigaçãoaconteceupormeiodoparecerconsubstanciado favorável(CAAE:35353614.1.0000.5152). $\mathrm{O}$ recrutamento dos participantes para a pesquisa aconteceu no formato bola de neve (Marcus, Weigelt, Hergert, Gurt, \& Gelléri, 2017). Assim, inicialmente, os pesquisadores informaram verbalmente aos contatos próximos que estavam recrutando psicólogos empreendedores para participar da investigação. Com o tempo, os psicólogos empreendedores buscavam espontaneamente os pesquisadores para participar da investigação.

Após o primeiro contato com a equipe executora, as entrevistas eram agendadas conforme a disponibilidade do participante. O local de realização das entrevistas buscou otimizar as condições contextuais para a livre expressão do participante (Wolgemuth et al., 2015). Assim, as entrevistas foram executadas individualmente por um pesquisador em uma sala de atendimento individual da clínica escola da instituição propositora. As entrevistas levaram em média 50 minutos para serem realizadas. Os participantes eram informados sobre o propósito da investigação, autorizavam a gravação da entrevista em áudio e assinalavam consentimento para participar da pesquisa por meio do Termo de Consentimento Livre Esclarecido (TCLE).

Após as entrevistas, os áudios capturados foram transcritos na íntegra por um membro da equipe executora. A transcrição dos áudios, conjuntamente ao arquivo de som, foi submetida aos demais membros da equipe de pesquisadores que, no formato de Comitê de Juízes, foram responsáveis por ouvir os áudios na íntegra e efetuar correções nas transcrições, com o intuito de garantir a fidedignidade do relato escrito frente à gravação (Silverman, 2017). Após apurar a verossimilhança entre a transcrição e o áudio, os arquivos de som foram apagados e a identificação dos participantes omitidas das transcrições, com o intuito de preservar seu anonimato.

\section{Análise de dados}

Os dados foram tabulados, com o intuito de gerar estatísticas descritivas, por meio do de LibreOffice Calc 6.2.3. A técnica empregada foi análise de conteúdo (Bardin, 2011). Os corpora de análise foram as transcrições das entrevistas. As unidades de análise foram definidas a posteriori, quando examinou-se a evocação dos temas pelo participante ao longo da entrevista. Para tanto, o material foi explorado inicialmente por leituras flutuantes, o que permitiu identificar as unidades de significados a serem categorizadas. O processo de categorização e subcategorização adotado foi do tipo frequentista (Campos, 2004). A frequência simples $\left(f_{i}\right)$ adotou como padrão a quantidade de entrevistas que a subcategoria se fez presente. Assim, esse indicador variou entre zero e seis. Por sua vez, na frequência acumulada $\left(f_{a}\right)$, foram computadas o número de vezes que a subcategoria temática foi mencionada. Desse modo, em uma mesma entrevista, a subcategoria na modalidade frequência acumulada poderia ser computada diversas vezes.

\section{Resultados}

A exploração do material permitiu a formulação de duas categorias gerais, a saber: motivações para empreender e desafios e dificuldades para empreender. A primeira categoria tratou sobre o as influências pessoais e contextuais que levaram o psicólogo a empreender. A segunda categoria abrangeu conteúdos relacionados às dificuldades enfrentadas pelos psicólogos empreendedores na proposição e gestão do próprio negócio.

Para a categoria motivações para empreender, foram elaboradas as subcategorias temáticas: a) insatisfação com o trabalho; b) autonomia e liberdade; c) flexibilidade de horário; d) mercado de trabalho; e) salário; e f) conciliar família e trabalho. De maneira geral, essas subcategorias evidenciaram que os motivos para os psicólogos buscarem o empreendedorismo se relacionaram com fatores psico-higiênicos no ambiente de trabalho e necessidades de subsistência. Essa categoria é sintetizada na Tabela 1.

Em relação à categoria desafios e dificuldades para empreender, foram propostas as seguintes subcategorias: a) gestão do próprio negócio; b) legislação e burocracia; e c) competidores e fluxo de clientes. De forma ampliada, as subcategorias associaram os desafios e dificuldades para abertura, capitalização inicial e padronização do negócio, relações com sócios, convênios, competidores e clientes, além de dificuldades de gestão do negócio, abrangendo lacunas da graduação que impactam na sobrevivência e rentabilidade do empreendimento. Essas subcategorias são dispostas na Tabela 2. 


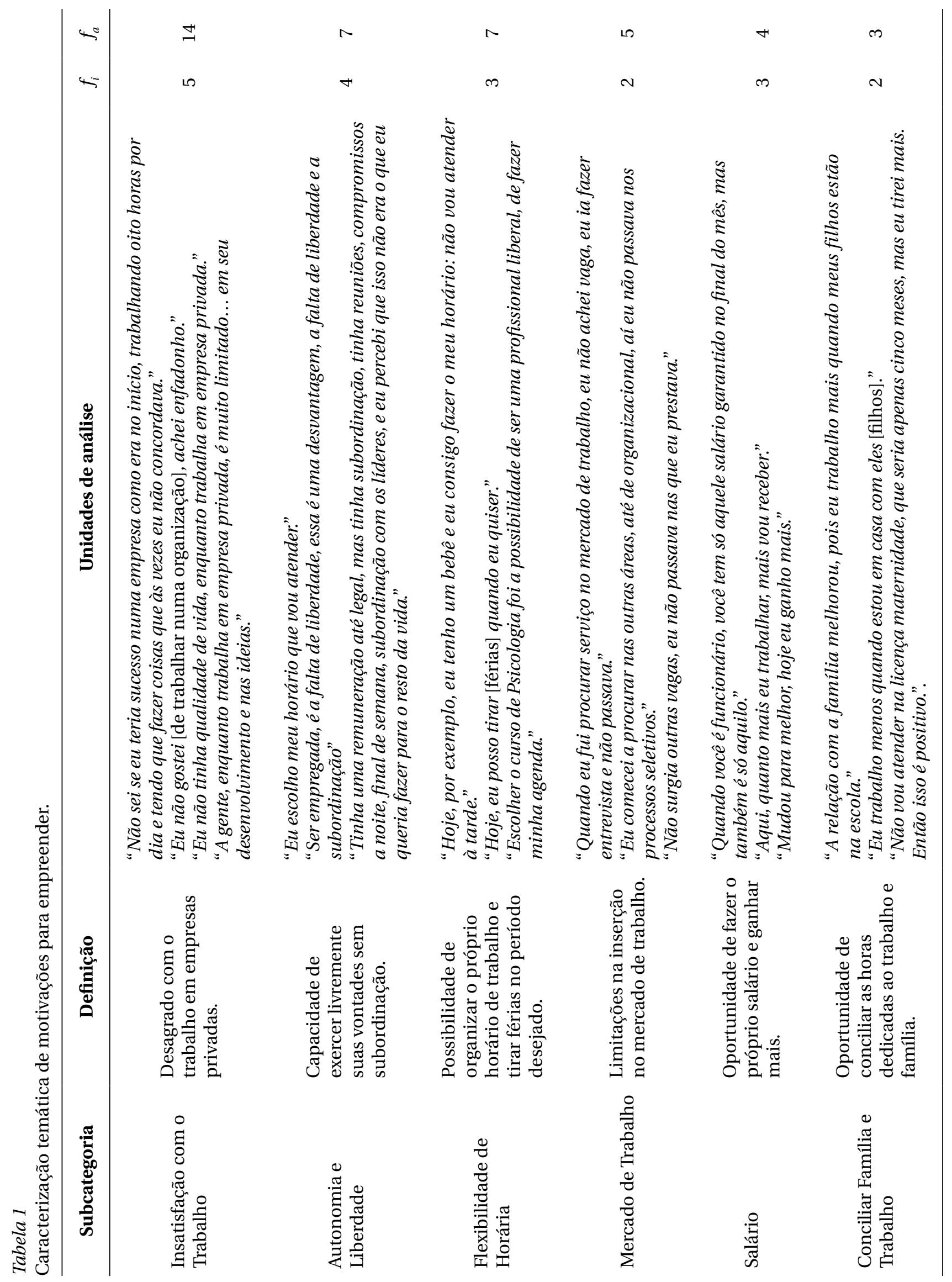




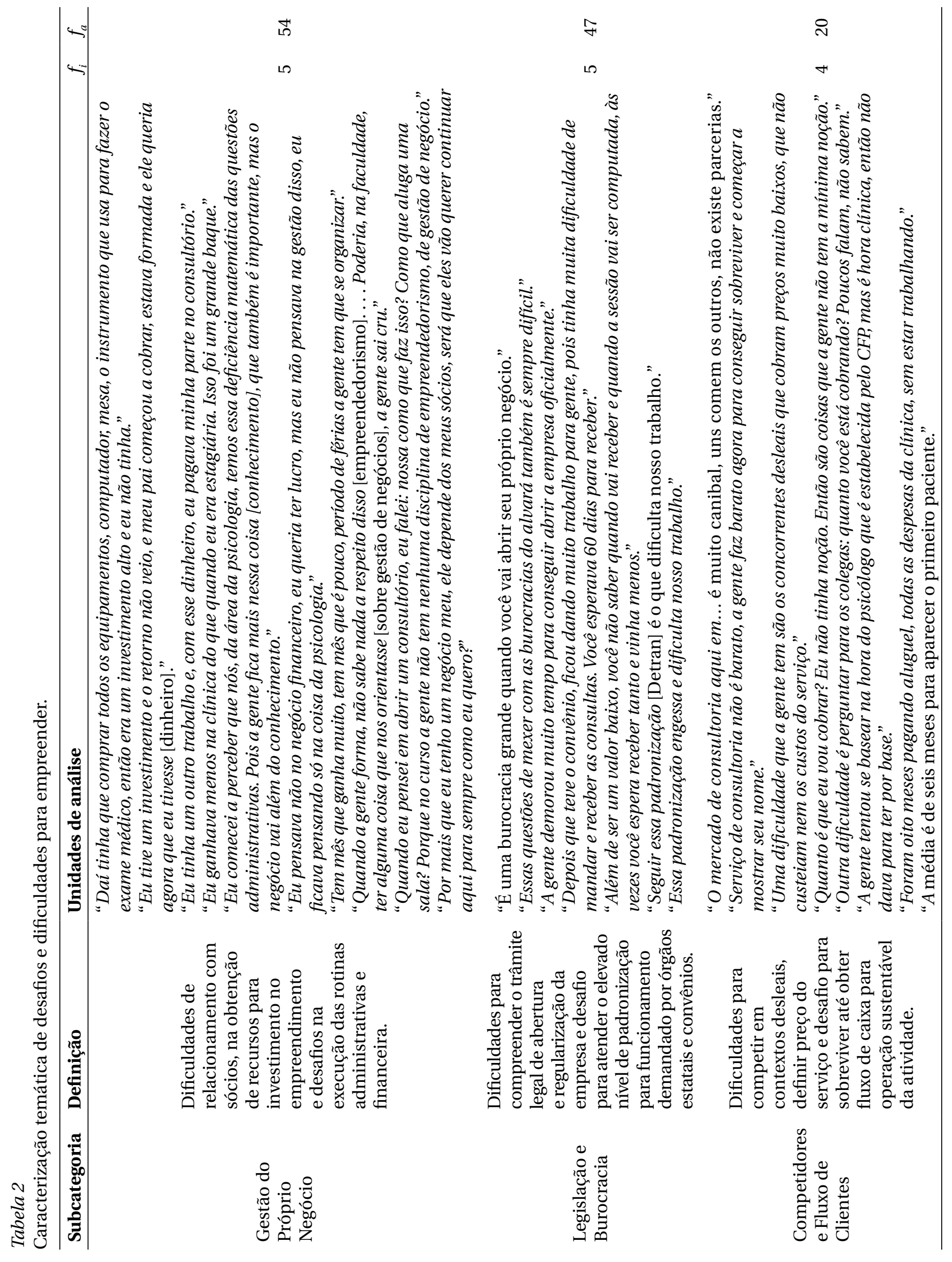




\section{Discussão}

Este estudo identificou as motivações, os desafios e as dificuldades vivenciados por psicólogos que atuam como empreendedores. Em relação às motivações para empreender, notaram-se que tanto elementos positivos, voltados à realização profissional, quanto negativos, ligados à insatisfação no trabalho, podem influenciar o psicólogo a optar pelo empreendedorismo.

Enfatizando-se os aspectos positivos relacionados às motivações para empreender, nota-se que os psicólogos entrevistados vislumbraram no empreendedorismo oportunidades para conciliar família e trabalho, obtendo maior flexibilidade horária e adquirindo autonomia sobre as próprias práticas por atuar como próprio chefe. A remuneração superior, quando comparada àquela aferida pelo psicólogo como colaborador de uma organização, também se mostrou relevante para motivá-los a empreender, o que é compatível com estudo empírico sobre a questão (Luzzi \& Sasson, 2016).

Especificamente sobre a subcategoria mercado de trabalho, é possível refletir a respeito do lugar do psicólogo no mercado de trabalho. Na verbalização, os entrevistados indicaram poucas vagas de trabalho para psicólogos com predominância de ofertas na área de psicologia organizacional. Os psicólogos também relataram que o trabalho nas empresas é enfadonho, limitado e sem qualidade de vida. Por essa razão, é possível apreender a necessidade de se aprofundar em questões relativas à formação e fazeres dos psicólogos nas organizações, uma vez que, a despeito da existência de vagas de trabalho na área, os entrevistados não enxergavam possibilidade de atuar de forma efetiva nesse contexto. Essas afirmações coincidem com elaboração recente sobre o tema, demandando pelo desenvolvimento futuro ações formativas que maximizem a atuação estratégica dos psicólogos nas empresas e em contextos ampliados (Ramos, Costa, \& Feitosa, 2017).

Voltando-se para os aspectos negativos associados às motivações para empreender, figura-se um contexto de trabalho precarizado na verbalização dos entrevistados, conjuntamente às poucas condições de inserção profissional como psicólogo, o que também motiva os indivíduos a optarem pelo empreendedorismo. Nesse sentido, é possível desmistificar que o processo empreendedor ocorre unicamente como aproveitamento de oportunidades, uma vez que os psicólogos entrevistados se motivaram pela necessidade de se estabelecer no exercício profissional (Tipu, 2016).
No que tange aos desafios e dificuldades enfrentados pelos psicólogos que empreendem, as subcategorias demonstraram que barreiras à proposição do empreendimento, o suporte obtido para manter o negócio e relações com agentes de interesse se mostram fundamentais para compreender o fenômeno na categoria. Analisando-se a categoria desafios e dificuldades, especificamente aquelas voltadas à gestão do próprio negócio, apura-se que as dificuldades vivenciadas pelos psicólogos para empreender são equivalentes àquelas enfrentadas por empreendedores em outros nichos (Nikolaev, Boudreaux, \& Palich, 2018). O empreendimento em psicologia, tal como nas demais áreas, requer captação de investimentos para tornar viável a iniciativa. Além disso, o psicólogo precisa adequar a proposta às exigências legais e burocráticas, bem como atender às normas dos órgãos regulamentadores que definem a padronização das práticas propostas em clínicas psicoterápicas e de avaliação psicológica para o trânsito, o que foi apresentado na subcategoria legislação e burocracia (Serviço Brasileiro de Apoio às Micro e Pequenas Empresas, 2018).

Uma alternativa razoável para enfrentar essas barreiras voltadas à gestão do negócio, burocracias e padronização podem acontecer por meio da apresentação das legislações e normas que regulamentam essas práticas aos alunos durante a graduação. Essa proposta poderia ser implementada por meio cooperações multidisciplinares entre departamentos universitários com expertise no tema ou por meio de disciplinas na graduação que envolvessem a formulação do plano de negócio pelo estudante com vivência prática em contextos de empresas juniores ou incubadoras de negócios (Silva \& Pratus, 2017). Contudo, diferentemente das propostas existentes atualmente para a implementação do empreendedorismo no ensino superior, em que as disciplinas sobre o tema são genéricas e equivalentes para todos os cursos, seria preciso considerar especificidades da profissão nessas ações de educação empreendedora, para que os alunos, de fato, pudessem aplicar o conteúdo de empreendedorismo e gestão dentro da psicologia, o que pode ter como inspiração propostas existentes em outros contextos (Imaginário, Cristo, Jesus, \& Morais, 2017).

Essa proposta de educação empreendedora direcionada para psicólogos na graduação poderia também otimizar as condições relacionadas às outras dificuldades e desafios apresentados pelos entrevistados. Os psicólogos empreendedores relataram ter dificuldade 
na gestão da própria empresa, alcançar lucratividade, lidar com a remuneração instável advinda do empreendimento, desconhecimento sobre quais preços cobrar e como conciliar os interesses entre os sócios. Eles também disseram que, em grande parte, essas limitações se associam com as lacunas na graduação que não tratavam sobre conteúdos de gestão e empreendedorismo em psicologia, apesar da importância do tema para a atuação profissional da categoria (Oliveira, Camargo, Feijó, Campos, \& Goulart-Júnior, 2016).

Nesse sentido, fomentar a educação empreendedora em cursos superiores de psicologia pode prestar contribuições às dificuldades supracitadas. Estratégias como aquelas desenvolvidas por meio da participação em empresas juniores tendem a ser eficazes para a promoção do empreendedorismo no nível superior (Cortez, Veiga, \& Salvador, 2019). Maior conhecimento de conteúdos e práticas de gestão e empreendedorismo também podem possibilitar aos psicólogos planejar com maior acurácia os próprios ganhos, solucionando as questões relativas à remuneração instável e estimação da lucratividade que se associam ao planejamento do empreendimento (Cortez \& Veiga, 2019). Ademais, maior planejamento e controle orçamentário permite que os psicólogos compreendam com maior propriedade os custos operacionais da atividade, otimizando a gestão do negócio como um todo e facilitando ao profissional estimar os preços do serviço prestado (Tehseen \& Ramayah, 2015).

Outro ponto que merece destaque é a subcategoria competidores e fluxo de clientes. Os psicólogos relataram dificuldade para colocar em prática os valores sugeridos como piso para a categoria e conseguir manter o negócio em funcionamento. Em relação ao preço dos serviços em psicologia, é importante salientar que o Conselho Federal de Psicologia (2018) vem desenvolvendo a tabela de honorários para possibilitar aos psicólogos um referencial sobre os valores a serem adotados na prática profissional. No entanto, relacionando-se o relato dos entrevistados sobre dificuldade dos psicólogos para definir os preços dos serviços com a verbalização dos participantes sobre competição desleal na área, pode-se questionar em que medida a proposta do CFP sobre honorários é passível de plena aplicação na prática dos psicólogos que empreendem em psicologia.

Sobre esse aspecto, cabe salientar avanços recentes da autarquia na tabela de honorários, que maximizou o leque de atividades relacionadas ao exercício da profissão e promoveu a atualização sazonal dos valores (Conselho Federal de Psicologia, 2018). Esses aspectos se mostram adequados por aumentar a gama de serviços passíveis de precificação e considerar flutuações ao longo do tempo. Contudo, ao não apresentar tabela de honorários com preços diferenciados por anos de experiência profissional, os recém-formados podem ter dificuldade em aplicá-la adequadamente.

Essa dificuldade pode ser exemplificada pelo relato integrado na subcategoria competição do mercado, em que os psicólogos definiram a concorrência como "canibal", algumas vezes não cobrindo nem o custo do próprio serviço. Infere-se que esse relato se relacione com condições nas quais o psicólogo empreendedor não consegue enxergar compatibilidade entre os honorários estabelecidos pelo CFP e aqueles passíveis de obtenção pela prestação de serviço psicológico. Nessas situações, motivado a iniciar a prática profissional, o psicólogo recém-formado pode propor o próprio serviço com preços inferiores aos custos do mercado, o que, inevitavelmente, resulta na insustentabilidade da própria prática profissional e desvalorização da categoria de forma geral. Isso pode acontecer principalmente em áreas concebidas como saturadas em relação à concorrência, tal como é o caso da psicologia clínica (Monteiro, Torres, Sousa, \& Coelho, 2014).

Nesse sentido, talvez seja razoável a intervenção das subsedes regionais do CFP com o intuito de gerar tabelas de honorários adequadas às realidades locais, sendo adicionadas às informações já existentes a categorização dos valores em relação ao tempo de prática profissional. Ressalta-se a questão do tempo de prática profissional como interveniente na definição do honorário, pois profissionais e empresas com maior experiência tendem a consolidar valores superiores na prestação de serviço ao longo dos anos (Gottschalk \& Alves, 2016). Assim, é fundamental que esse aspecto seja considerado para facilitar a orientação de jovens empreendedores em psicologia, que podem recair em ofertas de serviços psicológicos por valores insustentáveis por não conseguirem planejar e gerenciar adequadamente o próprio empreendimento.

Salienta-se ainda que a questão da prestação de serviços por preços insustentáveis é tão central ao tratar sobre empreendedorismo entre psicólogos que, inclusive, faz interface com as estratégias adotadas pelos profissionais para manter o empreendimento em funcionamento. Somadas às práticas de concorrência desleais, apresentadas na subcategoria 
competidores e fluxos de clientes, e atrasos em pagamentos, como aquelas relatadas na subcategoria legislação e burocracia, os psicólogos entrevistados mencionaram que precisam encontrar alternativas para sustentar o negócio em psicologia. Nessas condições, uma dessas alternativas é a dupla jornada de trabalho, que consiste na inserção profissional do psicólogo numa organização para injetar o salário no próprio empreendimento para manter os serviços, mesmo quando os empreendimentos demonstram rendimentos negativos. Ressalta-se que a falta de sustentabilidade do negócio e o uso desse tipo de estratégia tende a refletir ausência de planejamento por parte do propositor do empreendimento, o que também confirma os relatos dos entrevistados de que os psicólogos desconhecem as práticas de empreendedorismo e gestão (Hopp \& Greene, 2018).

Como exercício abdutivo, essa dinâmica permite conceber um contexto no qual, pelo desconhecimento das práticas de gestão e empreendedorismo resultantes de lacunas na formação, os psicólogos não sabem como planejar e gerenciar o próprio empreendimento, demandando que o negócio de prestação de serviço em psicologia seja sustentado pelos lucros aferidos pelo profissional em outro contexto de trabalho. Sobre isso cabe destacar que, sem otimizar as condições de inserção e sustentabilidade das práticas empreendedoras propostas pelos psicólogos, o que requer uma ampla revisão das diretrizes curriculares e competências a serem desenvolvidas por esses profissionais, é possível vislumbrar um contexto que os empreendimentos insustentáveis se tornem a tônica profissional da categoria. Com isso, as condições de trabalho empreendedor na psicologia tenderão à desvalorização por meio da concorrência desleal e "canibal", a qual dificultará a inserção do psicólogo como empreendedor (Fonseca, Ferreira, \& Costa, 2016).

Em um cenário com crescente flexibilização das relações trabalhistas, diminuição dos direitos dos trabalhadores e substituição da mão de obra técnica especializada por inovações advindas de inteligência computacional, é preciso refletir sobre os impactos de negligenciar a promoção do empreendedorismo na empregabilidade da categoria ao longo prazo (Antunes, 2014; Borges, 2017). Especificamente, cabe às entidades representativas da categoria, psicólogos e acadêmicos, encontrarem caminhos conciliatórios sobre o exercício profissional dos psicólogos, de forma que as propostas curriculares permitam a estes se inserirem como colaboradores nas instituições, mas sem que isso anule a possibilidade de desenvolvimento do empreendedorismo e de práticas de gestão de negócios, que também se mostram como caminhos para o exercício profissional na psicologia.

\section{Considerações finais}

A inserção do psicólogo no mercado acontece de diferentes formas nas organizações públicas e privadas, sendo também possível que o profissional seja dono de seu próprio negócio. Isso é particularmente importante ao se aventar a crescente precarização dos vínculos de trabalho, o que demanda por maximizar a empregabilidade da categoria por meio de inserções alternativas àquelas tradicionalmente ocupadas pelos profissionais. Ao longo deste estudo, discutiram-se os modos pelos quais os psicólogos relatam suas atividades empreendedoras, o que motiva esses profissionais a abrirem seu próprio negócio e, principalmente, quais desafios e dificuldades são encontrados pela categoria na abertura e administração dos empreendimentos em psicologia.

As motivações mais frequentes trataram do desagrado com o trabalho na iniciativa privada, a possibilidade aferir maiores lucros e ter um trabalho com maior autonomia, sem um gestor imediato. Os desafios e dificuldades incidiram sobre impasses na gestão do próprio negócio, enfrentamento de exigências legais e burocráticas e relações com competidores e fluxos de mercado, buscando integrar tais aspectos às competências a serem desenvolvidas ao longo da formação de psicólogo. A partir das evidências alcançadas por este estudo, nota-se a centralidade do CFP, das entidades representativas da categoria e das instituições de ensino superior de psicologia no fomento de ações profissionais e educativas voltadas ao tema.

No contexto atual, a formação acadêmica do psicólogo não orienta esses profissionais sobre práticas de gestão do próprio negócio, o que diminui a possibilidade de que a categoria possa empreender sem enfrentar as dificuldades e desafios supracitados. Convém destacar sobre esse aspecto que as questões geradas pelo estudo carecem, certamente, de um amadurecimento teórico e do acúmulo de evidências sobre o empreendedorismo entre psicólogos em diferentes contextos. Na corrente investigação, destaca-se entre as limitações o tamanho da amostra e a inclusão de profissionais de uma cidade do estado de Minas Gerais, o que demanda novos exercícios de 
investigação quantitativa e qualitativa para apreender com maior propriedade o tema.

Por fim, vale ressaltar que, devido à falta de pesquisas científicas sobre o empreendedorismo entre psicólogos, esta investigação contribui com um mapeamento qualitativo e inicial sobre o tema, o qual pode inspirar estudos futuros. Assim, como sugestão para estudos posteriores, recomenda-se verificar se os relatos apresentados tendem à saturação teórica em outras amostras e contextos, bem como desenvolver propostas de avaliações quantitativas sobre o tema, com o intuito de abranger uma descrição mais ampla sobre o fenômeno.

À guisa de conclusão, a principal contribuição deste estudo se apresenta na exposição da necessidade de serem incluídos conteúdos e práticas relativos ao empreendedorismo e gestão de negócios na graduação em Psicologia para potencializar o processo empreendedor entre psicólogos. Todavia lecionar a pura elaboração de planos de negócios não assegura que os profissionais terão mais facilidade de identificarem novas oportunidades de atuação. É preciso que haja mudança de postura em prol de uma cultura do empreendedorismo na psicologia, que endosse o desenvolvimento de estratégias de gestão e competências empreendedoras de forma mais ampla, o que inclui, inclusive, repensar a formação profissional psicólogo, tendo em vista as exigências recentes do mundo do trabalho que incidem sobre as possibilidades de atuação e empregabilidade da categoria profissional. Para tanto, a contribuição ativa de profissionais, pesquisadores e agentes políticos é demandada como uma atividade conjunta em favor de uma psicologia no plural, que inclua o empreendedorismo e a gestão em diferentes espaços entre o rol de atribuições e competências profissionais da categoria.

\section{Referências}

Alvord, S. H., Brown, L. D., \& Letts, C. W. (2004). Social entrepreneurship and societal transformation: An exploratory study. The Journal of Applied Behavioral Science, 40(3), 226-282. https:/ / doi.org/10.1177/0021886304266847

Andrade,A.L., Pissaia,A.T., Oliveira, M.Z.,\&Silva, M.Z. (2016).Características proteanas eafetossobrecarreira de estudantes de Psicologia. Estudos de Psicologia, 33(4), 677-688. http://dx.doi.org/10.1590/1982-02752016000400011

Andrade, L., Braga, G. C., Souza, J. A., \& Gomes, A. H. (2017). Percursos e experiências da psicologia no sistema único de assistência social em Joinville/SC. Revista de Ciências Humanas, 51(1), 230-248.

Antunes, M. A. M. (2014). A psicologia no Brasil: Leitura histórica sobre sua constituição. Educ. https://tinyurl.com/ yboeuht6

Bardin, L. (2011). Análise de conteúdo. Edições 70.

Bastos, A. V. B., \& Gondim, S. M. (2010). O trabalho do psicólogo no Brasil. Artmed. https://tinyurl.com/ydau5dbh

Borges, A. (2017). Os novos horizontes de exploração do trabalho, de precariedade e de desproteção. Cadernos do CEAS: Revista Crítica de Humanidades, 239(1), 713-741. http://dx.doi.org/10.25247/2447-861X.2016.n239.p713-741

Brasil. (2006). Norma operacional básica de recursos humanos do SUAS. Ministério do Desenvolvimento Social e Combate à Fome.

Campos, C. J. G. (2004). Método de análise de conteúdo: Ferramenta para a análise de dados qualitativos no campo da saúde. Revista Brasileira de Enfermagem, 57(5), 611-614. http://www.scielo.br/pdf/reben/v57n5/a19v57n5

Conselho Federal de Psicologia (2016). Nota técnica com parâmetros para atuação das e dos profissionais de psicologia no âmbito do Sistema Único de Assistência Social (SUAS). CFP.

Conselho Federal de Psicologia. (2018). Tabela de referência nacional de honorários dos psicólogos em reais. https://site.cfp.org.br/cfp-e-fenapsi-atualizam-tabela-de-referencia-de-honorarios-da-psicologia/

Conselho Federal de Psicologia, \& Centro de Referência Técnica em Psicologia e Políticas Públicas. (2011). Como os psicólogos e as psicólogas podem contribuir para avançar o Sistema Único de Assistência Social (SUAS): Informações para gestores e gestoras. https://site.cfp.org.br/wp-content/uploads/2011/12/GestoresSuasfinal.pdf

Cortez, P. A., \& Veiga, H. M. S. (2018). Características pessoais dos empreendedores: Clarificação conceitual dos construtos e definições da literatura recente (2010-2015). Estudos Interdisciplinares em Psicologia, 9(3), 58-79. https://10.5433/2236-6407.2018v9n3p58

Cortez, P. A., \& Veiga, H. M. S. (2019). Entrepreneurial intention at university. Ciencias Psicológicas, 13(1), 134-149. 
Cortez, P. A., Veiga, H. M. S., \& Salvador, A. P. (2019). Impacto de personalidade e empresas juniores para estimular potenciais empreendedores. Arquivos Brasileiros de Psicologia, 71(2), 179-192.

Fonseca, S. G., Ferreira, V. C. P., \& Costa, D. V. F. (2016). Novas relações de trabalho: Um estudo sobre psicólogos que atuam como profissionais liberais vinculados a uma instituição. Recape:Revista de Carreirase Pessoas, 5(3), 362-379. http://dx.doi.org/10.20503/recape.v5i3.22408

Francis, J. J., Johnston, M., Robertson, C., Glidewell, L., Entwistle, V., Eccles, M. P., \& Grimshaw, J. M. (2010). What is an adequate sample size? Operationalising data saturation for theory-based interview studies. Psychology and Health, 25(10), 1229-1245. https://doi.org/10.1080/08870440903194015

Gottschalk, M. V., \& Alves, P. (2006). Diferenciais de salários no setor de serviços. In J. A. Negri, F. Negri, \& D. Coelho (Eds.), Tecnologia, exportação e emprego (pp. 367-396). Ipea. http://www.ipea.gov.br/agencia/images/stories/ PDFs/livros/Cap_13.pdf

Hjorth, D., Holt, R., \& Steyaert, C. (2015). Entrepreneurship and process studies. International Small Business Journal, 33(6), 599-611. https://10.1177/0266242615583566

Hopp, C., \& Greene, F. J. (2018). In pursuit of time: Business plan sequencing, duration and intraentrainment effects on new venture viability. Journal of Management Studies, 55(2), 320-351. https://doi.org/10.1111/joms.12251

Imaginário, S., Cristo, E., Jesus, S. N., \& Morais, F. (2017). A criação e gestão de miniempresas na sala de aula: Opiniões dos alunos e professores participantes do Programa Empreender na Escola. Avances en Psicología Latinoamericana, 35(1), 23-42. http://dx.doi.org/10.12804/revistas.urosario.edu.co/apl/a.3710

Instituto Brasileiro de Geografia e Estatística. (2017). Pesquisa nacional por amostra de domicílios contínua. https://ww2.ibge.gov.br/home/estatistica/pesquisas/pesquisa_resultados.php?id_pesquisa=149

Instituto Brasileiro de Geografia e Estatística. (2019). Pesquisa nacional por amostra de domicílios contínua. https://agenciadenoticias.ibge.gov.br/agencia-sala-de-imprensa/2013-agencia-de-noticias/releases/24109pnad-continua-taxa-de-desocupacao-e-de-12-4-e-taxa-de-subutilizacao-e-de-24-6-no-trimestre-encerradoem-fevereiro-de-2019

Kallio, H., Pietilä, A. M., Johnson, M., \& Kangasniemi, M. (2016). Systematic methodological review: Developing a framework for a qualitative semi-structured interview guide. Journal of Advanced Nursing, 72(12), 2954-2965. https://doi.org/10.1111/jan.13031

Lamas, K. C. A., Ambiel, R. A., \& Silva, B. T. A. L. (2014). Vivências acadêmicas e empregabilidade de universitários em final de curso. Temas em Psicologia, 22(2), 329-340. http://dx.doi.org/10.9788/TP2014.2-05

Liñán, F.; Rodríguez-Cohard, J. C., \& Rueda-Cantuche, J. M. (2011). Factors affecting entrepreneurial intention levels: A role for education. International Entrepreneurship and Management Journal, 7(2),195-218. https://doi.org/ $10.1007 / \mathrm{s} 11365-010-0154-\mathrm{z}$

Luzzi, A., \& Sasson, A. (2016). Individual entrepreneurial exit and earnings in subsequent paid employment. Entrepreneurship Theory and Practice, 40(2), 401-420. https:// doi.org/10.1111/etap.12225

Marcus, B., Weigelt, O., Hergert, J., Gurt, J., \& Gelléri, P. (2017). The use of snowball sampling for multi source organizational research: Some cause for concern. Personnel Psychology, 70(3), 635-673. https://doi.org/10.1111/peps.12169

Mars, M. M., \& Rios-Aguilar, C. (2010). Academic entrepreneurship (re)defined: Significance and implications for the scholarship of higher education. Higher Education, 59(4), 441-460. https://doi.org/10.1007/s10734-009-9258-1

Minayo, M. C. S. (Org). (2012). Pesquisa Social: Teoria, método e criatividade. Vozes.

Monteiro, L. G., Torres, M. L. C., Sousa, L. G., \& Coelho, A. R. (2014). Perfil dos psicólogos inscritos na subsede leste do CRP-04. Psicologia: Ciência e Profissão, 34(4), 864-878. http://dx.doi.org/10.1590/1982-370000162013

Nikolaev, B. N., Boudreaux, C. J., \& Palich, L. (2018). Cross-country determinants of early-stage necessity and opportunity-motivated entrepreneurship: Accounting for model uncertainty. Journal of Small Business Management, 56(1), 243-280. https://doi.org/10.1111/jsbm.12400

Oliveira, I. R., Camargo, M. L., Feijó, M. R., Campos, D. C. D., \& Goulart-Júnior, E. (2016). Empreendedorismo social, pós-modernidade e psicologia: Compreendendo conceitos, atuações e contextos. Gerais: Revista Interinstitucional de Psicologia, 9(2), 290-311. http://pepsic.bvsalud.org/scielo.php?script=sci_arttext\&pid=S1983-82202016000200010

Ramos, C. C., Costa, T. D., \& Feitosa, I. O. (2017). Mapeamento de incoerências entre competências estabelecidas na formação do psicólogo organizacional e as requeridas pelo mercado de trabalho. Revista Psicologia Organizações e Trabalho, 17(2), 114-120. http://dx.doi.org/10.17652/rpot/2017.2.12866 
Ribeiro, M. I., Fernandes, A., \& Diniz, F. (2016). Propensão ao empreendedorismo em alunos do ensino superior: O caso de uma instituição pública do nordeste português. Revista de Empreendedorismo e Gestão de Micro e Pequenas Empresas, 1(2), 67-77. http://hdl.handle.net/10198/12873

Serviço Brasileiro de Apoio às Micro e Pequenas Empresas. (2018). Ideias de negócios: Como montar uma clínica de psicologia. http://www.sebrae.com.br/appportal/reports.do?metodo=runReportWEM\& nomeRelatorio=ideiaNegocio\&nomePDF=Cl\%C3\%ADnica\%20de\%20psicologia\&COD_IDEIA= 5ec2d69814961510VgnVCM1000004c00210a

Seixas, P. S., Coelho-Lima, F., \& Costa, A. L. F. (2010). Caracterização de dissertações/teses que versam sobre a profissão de psicólogo no Brasil. In O. H. Yamamoto \& A. L. F. Costa (Eds.), Escritos sobre a profissão de psicólogo no Brasil (pp. 59-96). EDUFRN.

Silva, J. F., \& Patrus, R. (2017). O “bê-á-bá” do ensino em empreendedorismo: Uma revisão da literatura sobre os métodos e práticas da educação empreendedora. Revista de Empreendedorismo e Gestão de Pequenas Empresas, 6(2), $372-401$.

Silverman, D. (2017). How was it for you? The interview society and the irresistible rise of the (poorly analyzed) interview. Qualitative Research, 17(2), 144-158. https://doi.org/10.1177/1468794116668231

Tehseen, S., \& Ramayah, T. (2015). Entrepreneurial competencies and SMEs business success: The contingent role of external integration. Mediterranean Journal of Social Sciences, 6(1), 50-61. https://doi.org/10.5901/mjss.2015.v6n1p50

Tipu, S. A. A. (2016). Comparing the behavior of opportunity and necessity driven entrepreneurs. International Journal of Entrepreneurship and Small Business, 27(1), 84-107. https://doi.org/10.1504/IJESB.2016.073359

Wolgemuth, J. R., Erdil-Moody, Z., Opsal, T., Cross, J. E., Kaanta, T., Dickmann, E. M., \& Colomer, S. (2015). Participants' experiences of the qualitative interview: Considering the importance of research paradigms. Qualitative Research, 15(3), 351-372. https://doi.org/10.1177/1468794114524222

\section{Dhayanne de Sousa Silva}

Psicóloga pela Universidade Federal de Uberlândia (UFU). Atua como pesquisadora voluntária no Laboratório de Psicologia Social e do Trabalho do Instituto de Psicologia da UFU, Uberlândia - MG. Brasil.

E-mail: dhay.psico@hotmail.com

(D) https://orcid.org/0000-0001-8954-5717

\section{Heila Magali da Silva Veiga}

Docente no Programa de Pós-Graduação em Psicologia do Instituto de Psicologia da UFU, Uberlândia - MG. Brasil.

E-mail: heila.veiga@gmail.com

(D) https://orcid.org/0000-0002-7429-8124

\section{Pedro Afonso Cortez}

Professor adjunto do Programa de Pós-Graduação em Psicologia da Saúde da Universidade Metodista de São Paulo, São Paulo - SP. Brasil.

E-mail: cor.afonso@gmail.com

(iD) https://orcid.org/0000-0003-0107-2033

Agradecimentos à Coordenação de Aperfeiçoamento de Pessoal de Nível Superior (Capes) pelo financiamento prestado na modalidade bolsa de doutoramento ao terceiro autor.

Endereço para envio de correspondência:

Universidade Federal de Uberlândia, Instituto de Psicologia. Av. Maranhão, s/n, Bloco 2C, Sala 2C54, Jardim Umuarama. CEP: 38405-318. Uberlândia-MG. Brasil. 
Recebido $12 / 07 / 2018$

Aceito 29/07/2019

Received $12 / 07 / 2018$

Approved 29/07/2019

Recibido $12 / 07 / 2018$

Aceptado 29/07/2019

Como citar: Silva, D. S., Veiga, H. M. S., Cortez, P. A. (2021). Motivações, desafios e dificuldades vivenciados por psicólogos empreendedores: Estudo qualitativo. Psicologia: Ciência e Profissão, 41, 1-13. https://doi.org/ $10.1590 / 1982-3703003207747$

How to cite: Silva, D. S., Veiga, H. M. S., Cortez, P. A. (2021). Motivations, challenges and difficulties experienced by entrepreneurial psychologists: Qualitative study. Psicologia: Ciência e Profissão, 41, 1-13. https://doi.org/ 10.1590/1982-3703003207747

Cómo citar: Silva, D. S., Veiga, H. M. S., Cortez, P. A. (2021). Motivación, desafíos y dificultades vividas por psicólogos emprendedores: Estudio cualitativo. Psicologia: Ciência e Profissão, 41, 1-13. https://doi.org/ 10.1590/1982-3703003207747 